\title{
Effects of soil profile on the transient performance of substation grounding system
}

\author{
Zulkurnain Abdul-Malek, Mohammad Shahrin Affendy Yaman, Muhammad Adnan \\ Institute of High Voltage and Current, School of Electrical Engineering, \\ Faculty of Engineering, Universiti Teknologi Malaysia, Malaysia
}

\begin{tabular}{l} 
Article Info \\
\hline Article history: \\
Received May 6, \\
Revised Jun 20, \\
Accepted Jul 8, \\
\hline Keywords: \\
Transient \\
GPR \\
Touch voltage \\
Step voltage \\
Grounding grid
\end{tabular}

Article Info

Article history:

Received May 6, 2020

Revised Jun 20, 2020

Accepted Jul 8, 2020

Grounding grid

\begin{abstract}
Lightning transient characteristic of the grounding grid is fundamental for optimum performance of lightning protection of a substation. In order to design an appropriate grounding system for such substation, it is important to study its transient characteristics because the high impulse current is significantly different compared to power frequency current. In this paper, substation grounding grid model was developed using CDEGS software to analyze the grid transient performance in terms of ground potential rise (GPR), touch voltage and step voltage when the grounding system is struck by a lightning impulse current. Several parameters, such as lightning current amplitude, feed point and the number of sub-grid, were altered to study their relationship with the transient performance. The maximum transient GPR, touch voltage, and step voltage increase as the lightning current amplitude increase. The maximum transient GPR and step voltage are the highest at the corner of the grounding grid while the maximum touch voltage is the highest at the centre of the grounding grid. In addition, the maximum transient GPR and step voltage decrease when the number of sub-grid increases. In contrast, the touch voltage slightly increases as the number of sub-grid increases. The maximum transient GPR, and step voltage are the highest at the 2-layer and the lowest at the uniform soil or single-layer soil
\end{abstract}

Copyright $\odot 2020$ Institute of Advanced Engineering and Science. All rights reserved.

\section{Corresponding Author:}

Zulkurnain Abdul-Malek,

Institute of High Voltage and High Current,

Universiti Teknologi Malaysia,

81310 Johor Bahru, Malaysia.

Email: zulkurnain@utm.my

\section{INTRODUCTION}

Electrical substations are the interface between parts of the distribution grid and transmission systems. When lightning strikes the substation protection system, large current flow may affect the substation equipment and electronic components before dissipating into the soil through the grounding system. Large electromagnetic fields may also be generated by the lightning surges, which are then translated into transient ground potential rise (GPR), touch voltage, and step voltage. These voltages may cause damage to the electronic equipment and as well as dangerous to the personnel working within reach of the substation. Besides, modern electronic circuits generally have weak signal levels and are sensitive to different kinds of electromagnetic disturbances. The unwanted electromagnetic fields induced by the lightning current may cause measurement error or may also cause breakdown to the electronic circuits. Therefore, it is important to properly design the grounding system so that the electromagnetic transient disturbance can be reduced to an acceptable level for safe and stable operation of the substation. In order to design a proper grounding system, it is fundamental to study its transient behaviour. The transient behaviour of a grounding system due to lightning impulse current is different from the fault current behaviour which is significantly influenced by several parameters. 
Typical results from a safety assessment exercise related to the transient GPR, step and touch voltages as well as ground resistance, state that, the grounding system performance and its safety are closely related to soil characteristics [1]. Many studies conclude that the higher soil resistivity will result in worst condition of the grounding system safety. In addition, the feed point of the lightning current is a key factor to determine the voltage distribution between any two points of the grounding grid. Many studies have proved that the transient GPR is much higher when the impulse current feed at the corner than feed at the centre of grounding grid for the same size of grounding grid [2-5]. Furthermore, when the amplitude of lightning current injected to grounding system increase, the electric fields around the grounding area are significantly increasing. As a result, the maximum transient GPR generated by an impulse current with high amplitude is much larger for the same grounding grid in the same soil resistivity [6]. In case of the interval between grounding conductors or sub-grid, the transient GPR will decrease significantly with the increment of sub- grid number. The increment of sub-grid number means more number of conductors used in grounding system to dissipate the impulse current. At the same time, the duration time of the maximum transient GPR response also shorter with the larger number of sub-grid [4].

As already proven by many of research studies [2-11], the behaviour of grounding systems energized by lightning with frequency spectrum in the $\mathrm{kHz}$ and $\mathrm{MHz}$ range is extremely different from the low frequency $(50 / 60-\mathrm{Hz})$ behaviour. This is because of the soil ionization phenomena and inductance of the system which may lead to the impulse response showing typically nonlinear behaviour. Hence, many papers have investigated the effect of parameters to analyse the behaviour of grounding systems when they are fed by impulse currents. However, little attention has been paid to the transient touch and step voltages when the grounding grid is buried in non-uniform soil. Therefore, in this study, several parameters, such as current amplitude, feed point and the number of sub-grid were varied to study their relationship with the transient GPR, touch and step voltages in uniform and non-uniform soil.

\section{RESEARCH METHOD}

In this study, CDEGS software package was used to accomplish the objectives of this project work. CDEGS is an engineering software tool designed to analyse problems related to the grounding system, electromagnetic fields, and electromagnetic interference. It consists of eight engineering modules but for this work, only RESAP, HIFREQ and FFTSES modules were applied. RESAP, HIFREQ, and FFTSES were used for soil resistivity, Electromagnetic Field, and Automated Fast Fourier Transforms (FFT) analysis respectively. CDEGS provides effective solutions to analyse behaviour of complex grounding grid when conductors are energized by lightning or other transients. The grounding grid was modelled using SESCAD.

\subsection{Computation of GPR, touch and step voltages in CDEGS}

Ground Potential Rise (GPR) is computed at the point where potential may attain by grounding conductor relative to a distant grounding point assumed to be at remote earth. When only buried grounding grid are modelled for example in CDEGS software, the potentials from the buried grounding conductors are computed and available, but the potentials of aboveground structures are unknown. For this reason, the touch potential cannot be computed. Therefore, based on CDEGS computation, the touch voltage is defined as the potential difference between the GPR and the potential of the nearest energized conductor segment at $1 \mathrm{~m}$ distance.

In CDEGS, for the computation of step voltage at a given point, the program needs to compute the potential difference between that point and a nearby point located at $1 \mathrm{~m}$ distance. However, the potential at that nearby point may be unavailable when the spacing of profile points specified by the user is larger than $1 \mathrm{~m}$ distance. Therefore, in CDEGS, the program will first determine the location of suitable test points close to the desired point and compute the worst step voltage between the desired point and all of those points.

\subsection{Grounding Grid Configuration}

A square grounding grid subject to a lightning strike was modelled as presented in Figure 1. Two grounding grid configurations were modelled with default conductors, $90 \mathrm{~m} \times 90 \mathrm{~m}$ mesh, and $11.25 \mathrm{~m} \mathrm{x}$ $11.25 \mathrm{~m}$ mesh, both buried at a depth of $0.5 \mathrm{~m}$. The lightning rod was simulated using a $5 \mathrm{~m}$ pole above the grid. The lightning rod was located at point $\mathrm{A}, \mathrm{B}$ and $\mathrm{C}$, hence these are the locations for the lightning current injection. The profiles referred to the lines used for results observation.

\subsection{The lightning surge current}

For the lightning current injection, the double-exponential formula was employed to fit with 10/350 $\mu$ s lightning current waveforms. The equation is given as

$$
I(t)=I_{m}\left(e^{-a . t}-e^{-b . t}\right)
$$


where $\alpha=2050$ and $\beta=564000$. Im is the amplitude of lightning current. The generated lightning current impulse was characterized with $10 \mu \mathrm{s}$ front time and $350 \mu \mathrm{s}$ tail time which are typical of lightning current. Figure 2 shows the lightning current waveform used in this study.

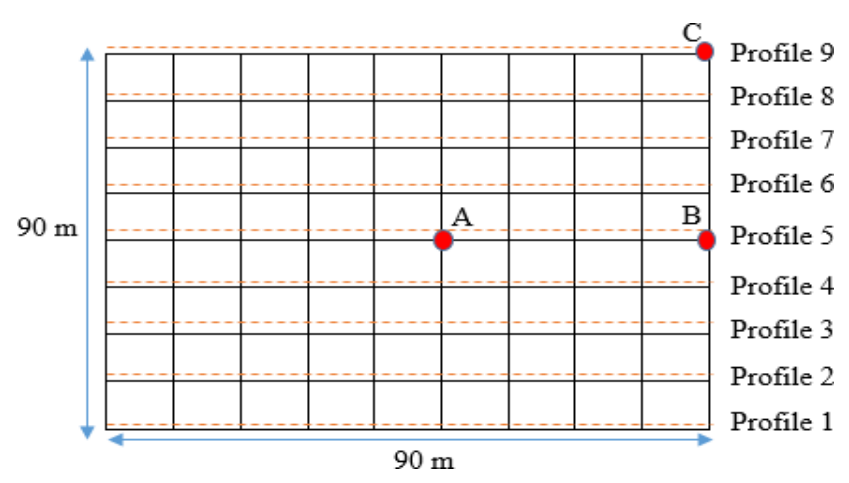

Figure 1. Grounding grid configuration

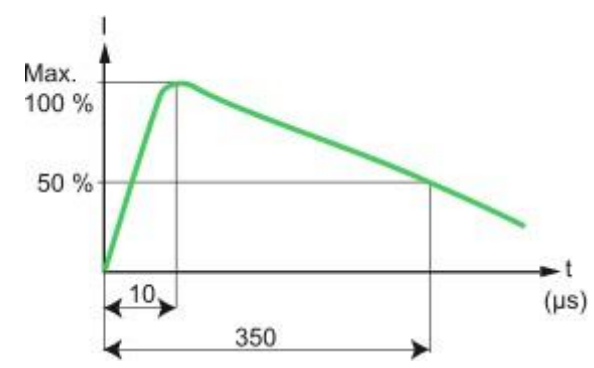

Figure 2. /350 $\mu$ s lightning current waveform used [12]

\subsection{Soil profile computation}

The RESAP (Soil Resistivity Analysis) computation module is used to determine equivalent soil profile models based on measured soil resistivity data. A uniform and non-uniform soil profile with the relative permittivity and relative permeability are set automatically by RESAP to be constant with 1.0 per unit respectively. The soil profile has been specified into three equivalent soil profiles which are the uniform or single layer, 2-layer, and 7-layer soils as shown in Table 1.

Table 1. Equivalent soil profiles from RESAP computation module

\begin{tabular}{cccc}
\hline Soil profile & Layer Number & Resistivity $(\Omega-\mathrm{m})$ & Thickness $(\mathrm{m})$ \\
\hline Uniform & 1 & 104.31 & Infinite \\
Non-uniform & 1 & 344.18 & 3.42 \\
& 2 & 28.03 & Infinte \\
& 1 & 264.74 & 0.61 \\
Non-Uniform & 2 & 465.31 & 0.20 \\
& 3 & 667.95 & 0.98 \\
& 4 & 119.57 & 0.20 \\
& 5 & 79.35 & 0.20 \\
& 6 & 54.36 & 16.61 \\
& 7 & 5.81 & Infinite \\
\hline
\end{tabular}

\subsection{Case study}

Three cases of studies were carried out. These cases are the influence of lightning current amplitude, the feed point, and the number of sub-grid to the transient performance of the substation grounding system (in terms of transient GPR, touch and step voltages produced). The lightning current with waveform 10/350 $\mu$ s and injection of lightning current at feed point 'A' of grounding grid were kept fixed but the amplitude of lightning current was varied as $10 \mathrm{kA}, 30 \mathrm{kA}$, and $50 \mathrm{kA}$ to study the effect of current amplitude. In case of feed point, three 
different feed points of lightning current were used as shown in Figure 1. In order to observe the influence of sub-grid number, several numbers of sub-grid, with $90 \mathrm{~m} \mathrm{x} 90 \mathrm{~m}$ size grounding grid had been chosen in this study. The number of sub-grid in the grounding system selected were 16, 36, and 64. A lightning current with $10 \mathrm{kA}$ peak, $10 / 350 \mu$ s was used for the feed point and sub-grid number cases. Equivalent soil profiles had been chosen for all cases as shown in Table 1. A certain observation line was chosen to observe and analyse the results.

\section{RESULTS AND ANALYSIS}

The results were divided into three measured variables, namely, the transient GPR, the touch voltage, and the step voltage. The effects of lightning current amplitude, feed point, and the number of sub- grid on each of these variables are reported.

\subsection{Effect of lightning current amplitude with different soil profiles}

Figure 3 shows the maximum transient GPR for feed point A. The maximum touch and step voltages are shown in Figures 4 and 5 respectively.

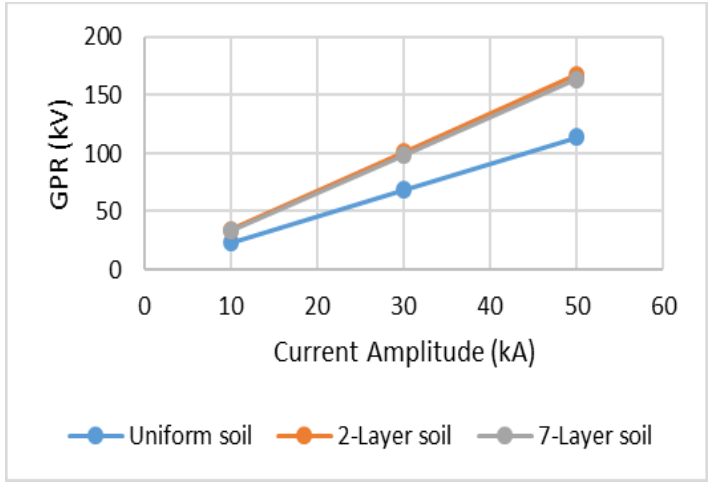

Figure 3. Effect of current amplitude to maximum transient GPR with $10 / 350 \mu$ s current at feed point A

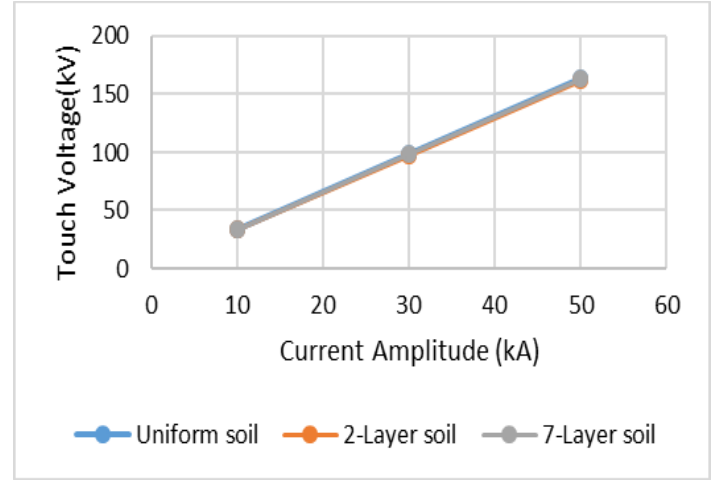

Figure 4. The effect of lightning current amplitude to the maximum transient touch voltage when injected by $10 \mathrm{kA}$ peak, $10 / 350 \mu$ s current at feed point $\mathrm{A}$

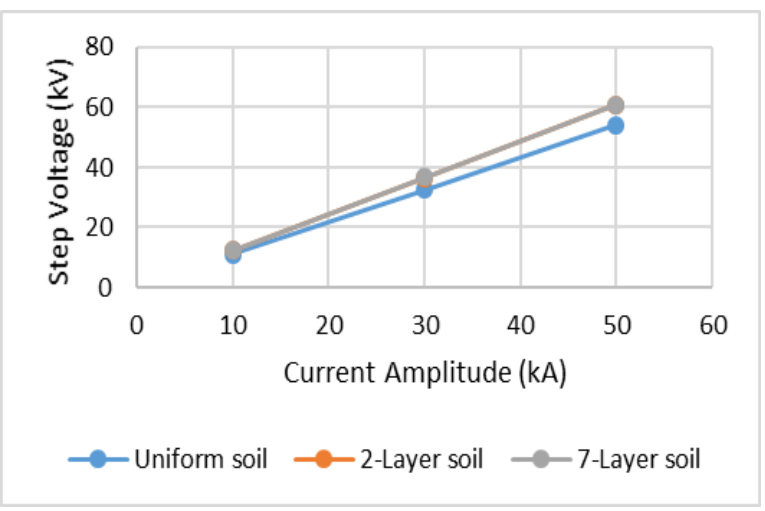

Figure 5. The effect of lightning current amplitude to the maximum transient step voltage when injected by $10 \mathrm{kA}$ peak, $10 / 350 \mu$ s current at feed point A

As shown in Figures 3, 4 and 5, the maximum transient GPR, step voltage and touch voltage linearly increases with the lightning current amplitude for all soil profiles. This is because the higher the amplitude of the lightning current, the more impulse current distributes around the grounding conductors. A lightning current waveform usually defined by amplitude, front time and tail time. Basically, the amplitude value in lightning current waveform has most significant effect on the transient performance rather than front time and tail time $[4,5]$. Besides, the higher amplitude of the lightning current gives the higher field gradient produced in soil around the grounding grid, which will make soil ionization more severe [13-16]. 


\subsection{Effect of feed point with different soil profiles}

Figure 6 shows the maximum transient GPR for feed point A. The maximum touch and step voltages are shown in Figures 7 and 8 respectively.

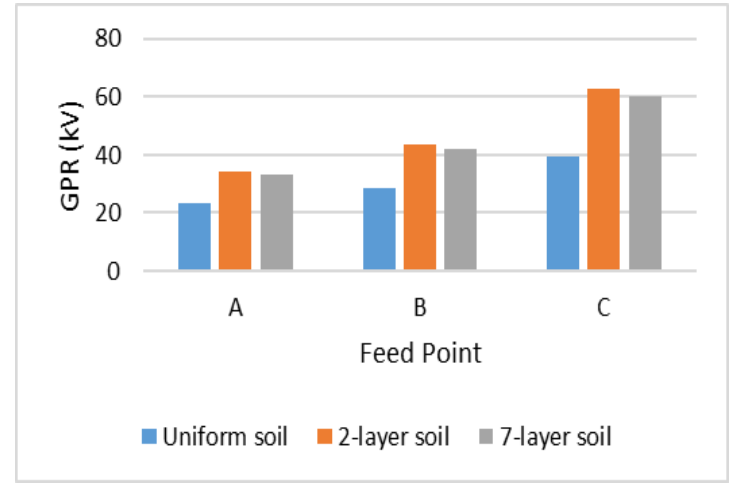

Figure 6. Effect of feed point to maximum transient GPR when injected by $10 \mathrm{kA}$ peak, $10 / 350 \mu$ s current

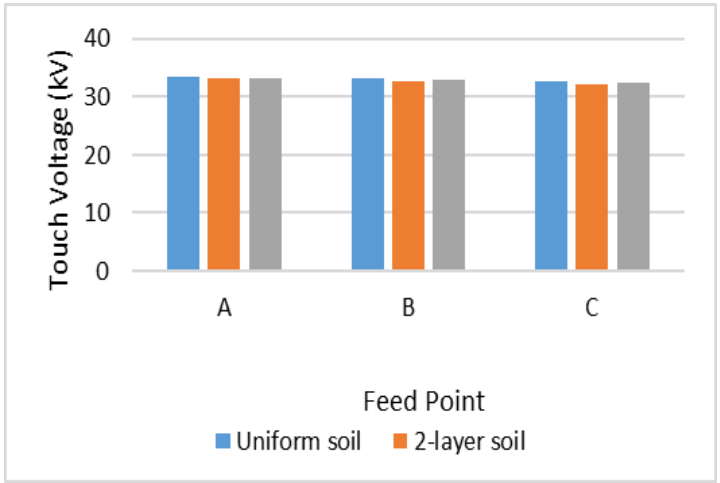

Figure 7. Effect of feed point to maximum transient touch voltage (injected by $10 \mathrm{kA}, 10 / 350 \mu$ s current)

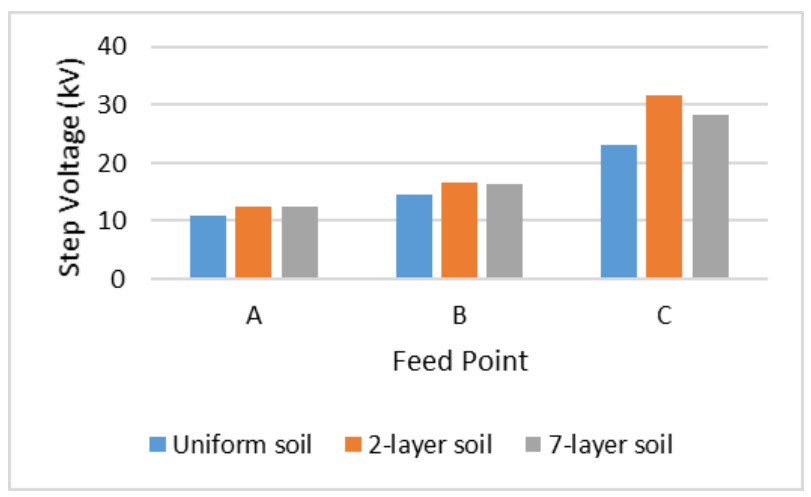

Figure 8. Effect of feed point to maximum transient step voltage when injected by $10 \mathrm{kA}, 10 / 350 \mu$ s current

As shown in Figures 6, 7 and 8 the maximum transient GPR and step voltage is the lowest at feed point A (centre) compared to feed point B (mid edge) and C (corner) for all soil profiles. This is because the feed point A has a larger effective area than the feed point $\mathrm{B}$ and $\mathrm{C}$. This means, all direction can be used for the lightning current to dissipate into the soil along with the grounding conductors. However, the maximum touch voltage is the highest at the feed point A compared to the feed point B and C. This is in contrast with the behaviour of transient GPR and step voltage to the feed point of grounding grid. This is because the potential of energized conductor at the point where a person touch, is almost similar for every location in the grounding grid. In spite of that, the transient GPR at the point where a person standing has different value for every location in the grounding grid. From the definition of touch voltage, the higher potential difference between the energized conductor and the transient GPR, the higher touch voltage is produced [17-18]. So, in this case, the potential difference is higher at the feed point $\mathrm{A}$ than the feed point $\mathrm{B}$ and $\mathrm{C}$.

\subsection{Effect of sub-grid number with different soil profiles}

Figure 9 shows the maximum transient GPR for feed point A. The maximum touch and step voltages are shown in Figures 10 and 11 respectively. As shown in Figures 9, 10 and 11, the maximum transient GPR, and step voltage are decreased when the number of sub-grid increases for all soil profiles. This is expected since the more number of sub- grid means the more conductors are used in grounding grid to dissipate impulse current into the soil. However, the maximum touch voltage has slightly increased when the number of sub-grid increases [19]. This is in contrast with the behaviour of transient GPR and step voltage to the number of sub-grid. This happens because of the potential difference between the energized conductor and the transient GPR is increases when the number of sub-grid increases. 


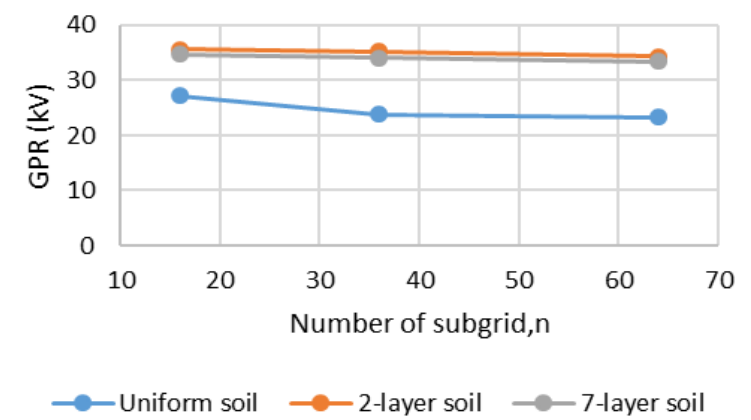

Figure 9. The effect of sub-grid number, $n$ to the maximum transient GPR when injected by 10 kA peak, $10 / 350 \mu$ s current at feed point A

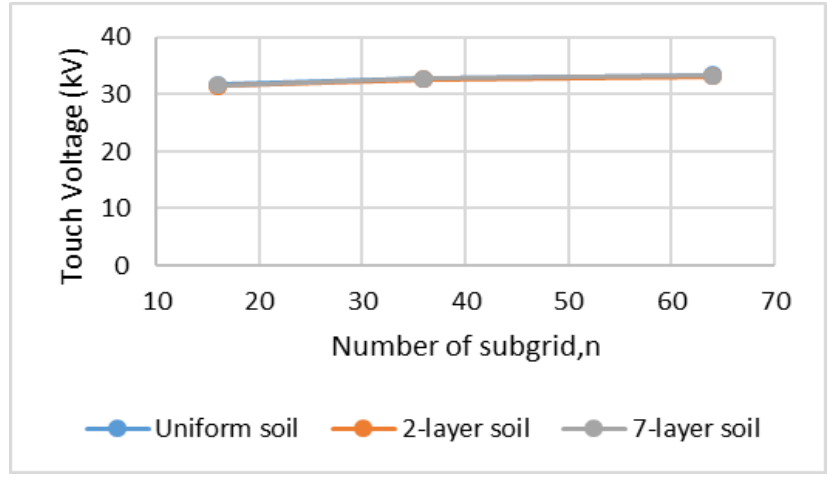

Figure 10. The effect of sub-grid number, $n$ to the maximum transient touch voltage when injected by $10 \mathrm{kA}$ peak, $10 / 350 \mu$ s current at feed point $\mathrm{A}$

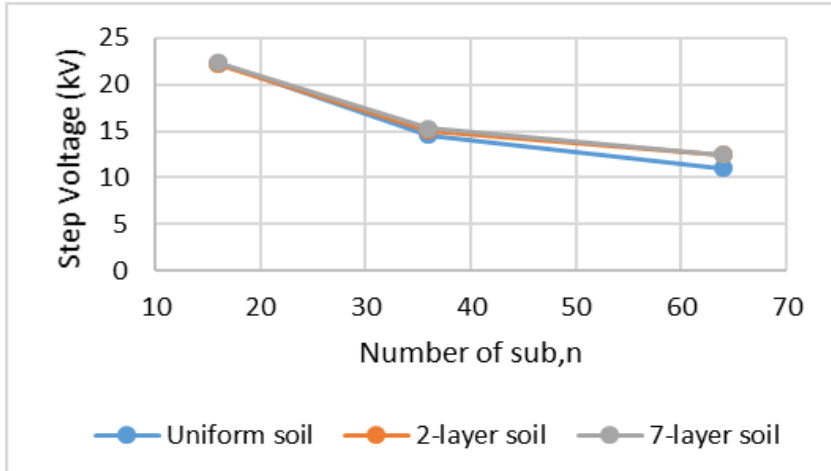

Figure 11. The effect of sub-grid number, $n$ to the maximum transient step voltage when injected by $10 \mathrm{kA}$ peak, $10 / 350 \mu$ s current at feed point $\mathrm{A}$

\subsection{Effect of soil profile to the maximum transient GPR, touch voltage and step voltage}

In terms of soil profile effect, Figures 3 to 11 show that the maximum transient GPR and step voltage are higher in non-uniform soil compared to uniform soil. Furthermore, the maximum transient GPR and step voltage in non-uniform soil are higher in 2-layer compared to 7-layer. This happens because the overall resistance and impedance of grounding grid are influenced by the resistivity of the layer where the grounding grid is buried [20-23]. In case of uniform soil, when the depth of a grounding grid increases, the ground resistance decreases but for non-uniform soil or multilayer soil, this is not always true, even if the change of grounding grid depth is confined within one layer. 
Generally, the grounding resistance values are greatly dependent on the layer in which the grounding grid is located [24-27]. When it is located in a layer has low resistivity, the grounding resistance is low, while when it is located in a layer has high resistivity, the grounding resistance is high. In this study, the grounding grid was buried at depth $0.5 \mathrm{~m}$, which is located within the first layer for all soil profiles. Since the 2-layer has the highest soil resistivity in the first layer, hence the 2-layer is the highest transient GPR and step voltage compared to 7-layer and uniform soil. However, the maximum touch voltage has no significant effect on the variation of soil profiles. The touch voltage is greatly dependent on the potential difference between the energized conductor and the transient GPR. Therefore, the analysis of touch voltage, in this case, can be neglected.

\section{CONCLUSION}

The influence of different parameters on the transient performance of the grounding system with different soil profiles had been carried out by using CGEDS software. From this study, the performance of transient GPR, touch voltage and step voltage of grounding grid are significantly dependent on the variation of lightning current amplitude, feed point and number of sub-grid as well as properties of soil. The lower transient GPR, touch and step voltages, the more safety of substation grounding system.

As shown in the plotted graphs, the maximum transient GPR, touch voltage, and step voltage increase as the lightning current amplitude increases. In the case of injection current location, the maximum transient GPR and step voltage are the highest at the feed point $\mathrm{C}$. Besides, the maximum touch voltage is the highest at feed point A. The maximum transient GPR and step voltage decrease when the number of subgrid increases. However, the maximum touch voltage slightly increases as the number of sub-grid increases. The maximum transient GPR, and step voltage are the highest at the 2-layer and the lowest at the uniform soil or single-layer soil. However, the maximum touch voltage has no significant effect on the variation of soil profiles. The results presented in this work can be helpful for an engineer to design or upgrade a substation grounding system, especially for the use of the protection against lightning. The results can also be used as a benchmark for future studies in this area.

\section{ACKNOWLEDGEMENTS}

The authors wish to thank the Ministry of Higher Education (MOHE) and Universiti Teknologi Malaysia (Research Vote Nos. 4F828 and 18H10) for the financial aid.

\section{REFERENCES}

[1] IEEE Guide for Safety in AC Substation Grounding Std 80-2000, February, 2000.

[2] L. D. Grcev and M. Heimbach, "Frequency dependent and transient characteristics of substation grounding systems," IEEE Power Eng. Rev., vol. 12, no. 1, pp. 172-178, 1997.

[3] Y. Gao, J. He, R. Zeng, and X. Liang, "Impulse transient characteristic of grounding grids," 3rd Int. Symp. Electromagn. Compat., pp. 276-280, 2002.

[4] R. Zeng, X. Gong, J. He, B. Zhang, and Y. Gao, "Lightning impulse performances of grounding grids for substations considering soil ionization," IEEE Trans. Power Deliv., vol. 23, no. 2, pp. 667-675, 2008.

[5] D. Lian, Z. Bo, H. Jinliang, X. Leishi, L. Qian, "Experimental study on transient characteristics of grounding grid for substation," 2016 33rd Intr. Conf. Lightning Protec., pp. 1-6, 2016.

[6] W. Jia, "Double-exponential expression of lightning current waveforms," 2006 4th Asia-Pacific Conf. Environ. Electromagn., pp. 320-323, 2006.

[7] W. Xiong and F. P. Dawalibi, "Transient performance of substation grounding systems subjected to lightning and similar surge currents," IEEE Trans. Power Deliv., vol. 9, no. 3, pp. 1412-1420, 1994.

[8] F. P. Dawalibi, W. Xiong, and J. Ma, "Transient performance of substation structures and associated grounding systems," IEEE Trans. Ind. Appl., vol. 31, no. 3, pp. 520-526, 1995.

[9] G. Xuehai and H. E. Jinliang, "Electromagnetic interference on secondary systems of substation caused by incoming lightning stroke," IEEE Int. Symp. Electromagn. Compat., pp. 212-216, 2007.

[10] L. A. Salgado, J. L. Guardado, J. Torres, and E. O. Hernández, "Transient analysis of grounding systems under lightning strikes considering soil ionization," Conf. Rec. - IAS Annu. Meet., pp. 2-8, 2010.

[11] C. Tian, Y. Zhang, L. Cai, J. Wang, S. Huang, and Y. Wang, "Lightning transient characteristics of a 500-kV substation grounding grid," 2011 7th Asia-Pacific Int. Conf. Light. APL2011, pp. 711-715, 2011.

[12] K. Bhumkittipich, B. Topradith, and T. Suwanasri, "Analysis of lightning phenomena for underground petroleum pipeline system," Energy Procedia, vol. 34, pp. 148-158, 2013.

[13] M. Mokhtari, Z. Abdul-Malek, and G. B. Gharehpetian, "A critical review on soil ionisation modelling for grounding electrodes," Arch. Electr. Eng., vol. 65, no. 3, pp. 449-461, 2016. 
[14] M. Mokhtari, Z. Abdul-Malek, and Z. Salam, "An improved circuit-based model of a grounding electrode by considering the current rate of rise and soil ionization factors," IEEE Trans. Power Deliv., vol. 30, no. 1, pp. 211-219, 2015.

[15] M. Mokhtari, Z. Abdul-Malek, and Z. Salam, "The effect of soil ionization on transient grounding electrode resistance in non-homogeneous soil conditions," Int. Trans. Electrical Energy Systems, vol. 26, no. 7, pp. 1462-1475, 2016.

[16] M. Mokhtari, Z. Abdul-Malek, and G. B. Gharehpetian, "A new soil ionization model for grounding electrodes," Int. Trans. Electrical Energy Systems., vol. 27, no. 3, pp. 1-15, 2017.

[17] M. Nayel, Z. Jie, H. Jinliang, C. Zongyuan, and W. Qi, "Study of step and touch voltages in resistive/capacitive ground due to lightning stroke," Proc. - Fourth Asia-Pacific Conf. Environ. Electromagn. CEEM’2006, pp. 56-60, 2006.

[18] C. S. Payshetti, H. T. Jadhav, and S. Kulkarani, "Analysis of grounding grid of substation," IEEE Int. Conf. Circuit, Power Comput. Technol. ICCPCT 2017, pp. 1-5, 2017.

[19] L. Arumugam, "Effect of grounding parameters on the voltage profile of the grounding system," Thesis, Universiti Teknologi Malaysia, June, 2018.

[20] M. Mokhatri and Z. Abdul-Malek, "The effect of grounding electrode parameters on soil ionization and transient grounding resistance using electromagnetic field approach," Appl. Mech. Mater., vol. 554, pp. 628-632, 2014.

[21] Adetoro Saheed Ayodeji, "Effect of soil resistivity and grounding system on the voltage distribution in surrounding earth of a communication tower structure during a lightning strike," Thesis, Universiti Teknologi Malaysia, January, 2014

[22] M. Kižlo and A. Kanbergs, "The causes of the parameters changes of soil resistivity," The 50th Inter. Sci. Conf. Power and Elect. Eng., pp. 43-46, 2009.

[23] Fluke, Earth Ground Resistance, Appl. note 2633834 B-EN-N Rev A, 2006, p. 16.

[24] B. E. Kushare and M. G. Unde, "Impact of seasonal variation of soil resistivity on safety of substation grounding system," Fifth Int. Conf. Adv. Recent Technol. Commun. Comput. (ARTCom 2013), pp. 173-182, 2013.

[25] S. Nikolovski, G. Knežević, and Z. Baus, "Assessment of step and touch voltages for different multilayer soil models of complex grounding grid," Int. J. Electr. Comput. Eng., vol. 6, no. 4, pp. 1441-1455, 2016.

[26] D. Prasad and H. C. Sharma, "Significance of step and touch voltages," Int. J. Soft Comput. Eng., vol. 1, no. 5), pp. 193- 197, 2011.

[27] F. P. Dawalibi, J. Ma, R. D. Southey, "Behaviour of grounding systems in multilayer soils: a parametric analysis," IEEE Trans. Power Deliv., vol. 9, no. 1, pp. 334-342, 1994. 